\title{
Generation Control of ZnO Nanoparticles Using a Coaxial Gas-Flow Pulse Plasma Ar/O 2 Plasma
}

\author{
Hiroki Shirahata and Satoru Iizuka \\ Department of Electrical Engineering, Tohoku University, Aramaki Aza-Aoba 6-6-05, Aoba-ku, Sendai 980-8579, Japan \\ Correspondence should be addressed to Satoru Iizuka; iizuka@ecei.tohoku.ac.jp
}

Received 1 July 2015; Accepted 25 August 2015

Academic Editor: Raphael Schneider

Copyright (C) 2015 H. Shirahata and S. Iizuka. This is an open access article distributed under the Creative Commons Attribution License, which permits unrestricted use, distribution, and reproduction in any medium, provided the original work is properly cited.

Generation of $\mathrm{ZnO}$ nanoparticles was investigated using a coaxial gas-flow pulse plasma. We studied how zinc atoms, sputtered from a zinc target, reacted with oxygen in a plasma and/or on a substrate to form $\mathrm{ZnO}$ nanoparticles when the discharge parameters, such as applied pulse voltage and gas flow rate, were controlled in an $\mathrm{O}_{2} / \mathrm{Ar}$ plasma. The formation processes were estimated by SEM, TEM, and EDX. We observed many ZnO nanoparticles deposited on Si substrate. The particle yield and size were found to be controlled by changing the experimental parameters. The diameter of the particles was typically $50-200 \mathrm{~nm}$.

\section{Introduction}

Zinc oxide $(\mathrm{ZnO})$ is an $\mathrm{n}$-type semiconductor with a wide band gap of $3.37 \mathrm{eV}$, a large exciton binding energy of $60 \mathrm{meV}$, and high thermal and mechanical stability. Therefore, there are many applications of $\mathrm{ZnO}$ such as transparent electrodes, light-emitting diodes (LEDs), and semiconductor materials [1-6].

$\mathrm{ZnO}$ nanostructures such as nanorods and nanoparticles showed a definite promise for an employment in nanoscale devices, including field emitters, UV lasers, field-effect transistors, dye sensitized solar cells, and gas sensors. In addition, spherical $\mathrm{ZnO}$ nanoparticle was expected for an application to quantum dot solar cells [7-9].

In general, $\mathrm{ZnO}$ nanorods and nanoparticles have been produced by vapor-liquid-solid (VLS) process, chemical vapor deposition (CVD), and liquid laser melting method. Our group is focusing on a plasma process for the growth of oxide metal nanostructures [10-14]. This process is superior to the other processes for low temperature and large area deposition. Besides, when the energy of plasma is controlled, $\mathrm{ZnO}$ thin films or $\mathrm{ZnO}$ nanoparticles can be selectively produced. However, very few studies have dealt with energycontrolled plasma.

In this study, the formation of $\mathrm{ZnO}$ nanoparticles was investigated by focusing on its dependence on the discharge parameters such as applied pulse voltage $V_{p}(-500$ to $-800 \mathrm{~V})$ and total gas flow rate of $\mathrm{Ar} / \mathrm{O}_{2}$ (20 to $100 \mathrm{sccm}$ ) under the fixed total pressure $\left(30 \mathrm{~Pa}\right.$ ) of working gases of $\mathrm{Ar}$ and $\mathrm{O}_{2}$.

\section{Experimental Setup}

Figure 1 shows a schematic of the experimental apparatus [14]. The experiment was performed in low-pressure plasma by employing reactive ion sputtering. As a source of $\mathrm{Zn}, \mathrm{Zn}$ rod electrode (diameter $2 \mathrm{~mm}$ ) was used and installed in a glass tube of $6 \mathrm{~mm}$ in inner diameter and $1 \mathrm{~mm}$ thick. The flow rates of $\mathrm{Ar}$ and $\mathrm{O}_{2}$ gases were adjusted by mass flow controllers independently and the mixed gas was introduced into a stainless tube. A pulse voltage $V_{p}$ with pulse width of $5 \mu$ s was employed for the plasma production.

Partial pressure ratio of $\mathrm{Ar} / \mathrm{O}_{2}$ and pulse repetition frequency were fixed during the experiment. The substrate used was Si wafer ( $\mathrm{p}$ type, crystal orientation $\langle 100\rangle$ ). The electrode configuration including the substrate position was also fixed. The distance between the electrode tip and Si substrate was fixed at $5 \mathrm{~mm}$. The wavelength of the optical emission from the plasma was monitored and evaluated by the optical emission spectroscope (OES). $\mathrm{ZnO}$ deposition was analyzed by scanning electron microscope (SEM), transmission electron microscope (TEM), and energy dispersive 


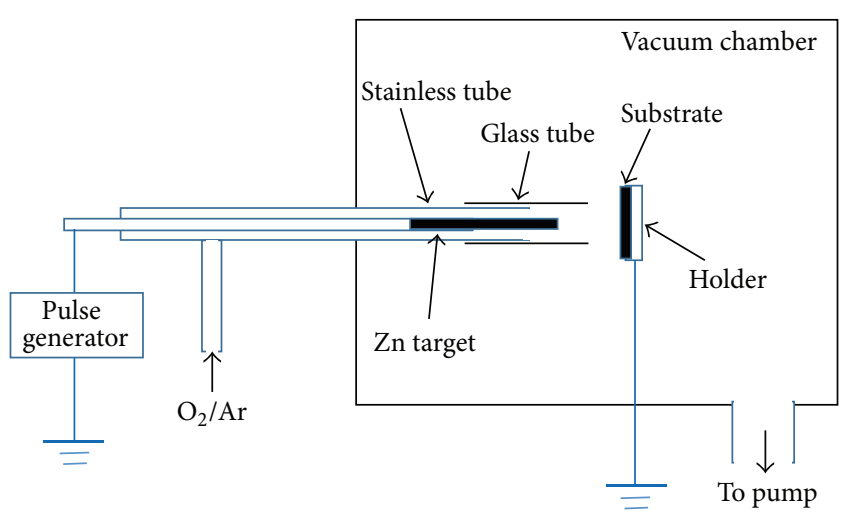

FIGURE 1: Experimental apparatus.

X-ray spectroscopy (EDX). Since the length of the glass tube and the substrate plate was small $(\sim 10 \mathrm{~mm})$, the pressure in the discharge region was nearly as much as that in the vacuum chamber. Typically, the gas flow rate ratio of argon to oxygen was fixed at $\mathrm{Ar} / \mathrm{O}_{2}=1 / 1$ under a total pressure of $\mathrm{Ar}$ and $\mathrm{O}_{2}$ fixed at $30 \mathrm{~Pa}$.

\section{Experimental Results}

The experiment was conducted when $\mathrm{O}_{2}$ and Ar flow rates were 25 and $25 \mathrm{sccm}$, respectively; that is, $\mathrm{O}_{2} / \mathrm{Ar}=1 / 1$, and the total pressure was $30 \mathrm{~Pa}$. From the results of optical emission spectroscopy (OES) during the deposition, the emission spectra of $\mathrm{Ar}$ and $\mathrm{O}_{2}$ were observed, but those of $\mathrm{Zn}$ were not observed. The results implied that our experimental condition was in an oxide mode. That is, the zinc target electrode surface was oxidized to form $\mathrm{ZnO}$ thin layer during the sputtering deposition.

3.1. Time Dependence of Nanoparticle Deposition. Figure 2 shows typical SEM images of the depositions on the Si substrate with a deposition time as a parameter at applied voltage $-650 \mathrm{~V}$. Very few particles were observed at 10 minutes after turning on the plasma. At 90 minute, we clearly observed many particles deposited on the Si substrate. The changes of the particle density and the particle size were plotted in Figure 3 as a function of deposition time. For 10minute deposition an average diameter of the particles was $55.3 \mathrm{~nm}$ and their density was 0.25 particles $/ \mu \mathrm{m}^{2}$. However, for 30-minute deposition, the average diameter of particles was increased to $137 \mathrm{~nm}$, but their density was still 0.23 particles $/ \mu \mathrm{m}^{2}$. As the deposition time was further increased, both the diameter and density were increased. Finally, we got average diameter of $207 \mathrm{~nm}$ and the density of 1.3 particles $/ \mu \mathrm{m}^{2}$ for 90 -minute deposition.

As shown by the SEM image in Figure 2(c), the particle size seemed to be very uniform. In order to evaluate the uniformity of particle size, particle size distribution function was taken by sampling the particles within an area of $10 \mu \mathrm{m}$ $\times 10 \mu \mathrm{m}$, which was chosen randomly. Figure 4 shows the particle size distribution function for the particles deposited after 90 minutes shown in Figure 2(c). We got a very sharp profile with a mean size of $208 \mathrm{~nm}$. Half width of the distribution was about $20 \mathrm{~nm}$; therefore almost all particles have a size within $208 \pm 10 \mathrm{~nm}$. Therefore, the uniformity or the irregularity was within $\pm 5 \%$. The reason why the particle size was so uniform was closely related to the growth mechanism of these particles. The reason was discussed in Section 4.

3.2. Identification of Nanoparticles. Figure 5(a) is a magnified SEM image for the 90-minute deposition. We can observe many particles deposited on the background layer with fine structures. Cross-sectional TEM image of Figure 5(a) is shown in Figure 5(b), where we find that two nanoparticles are adhered to the background surface layer deposited on Si surface. The particle size was $100 \mathrm{~nm}$ and the shape was a little bit irregular with polygon surface. Many triangularshape corners were seemed to grow on the particle surface. This structure meant that many polycrystals were coagulated to form a nanoparticle. On the other hand, the background layer, to which nanoparticle was adhered, consisted of columnar rod structure. Fine surface structures of the background layer shown in Figure 5(a) were identified as a top view of such columnar layers.

It should be noted that the nanoparticles were not buried in the background layer. The nanoparticles were simply adhered to the top surface of the background layer. This result showed important information on the formation mechanism of nanoparticles. It should be also noted that the polygon surface structure of nanoparticles shown in Figure 5(b) indicated that these nanoparticles consisted of polycrystals, as described above.

In order to identify the atomic composition of such nanoparticles, EDX analysis was carried out. SEM image in Figure 5(c) shows a typical particle, which is subjected to EDX analysis. As shown by the spectrum in Figure 5(d), both zinc and oxygen were detected together with intense signals coming from $\mathrm{Si}$ substrate. No other atomic species were detected as a contamination contained in the nanoparticles. From this result, it was confirmed that the nanoparticles only consisted of zinc and oxygen. Here, atomic ratio of $\mathrm{Zn} / \mathrm{O}_{2}$ was not estimated from this signal, because signal of $\mathrm{O}_{2}$ came from both $\mathrm{ZnO}$ and oxidized silicon surface $\mathrm{SiO}_{2}$.

Figure 6 shows Raman spectra of the deposited sample shown in Figure 5(a) (upper trace) and standard $\mathrm{ZnO}$ sample (lower trace). It is known that $\mathrm{ZnO}$ has a single peak at $440 \mathrm{~cm}^{-1}$ as shown in the lower trace. There also appeared a sharp peak at $440 \mathrm{~cm}^{-1}$ in the upper trace together with a strong peak of $\mathrm{Si}$ at $530 \mathrm{~cm}^{-1}$. Therefore, our sample containing nanoparticles consisted of $\mathrm{ZnO}$ crystal. Although the laser spot diameter was about $2 \mu \mathrm{m}$, larger than the size of nanoparticles, the signal in Figure 6 showed a growth of $\mathrm{ZnO}$ crystal on $\mathrm{Si}$ substrate including nanoparticles. By taking their sharp polygon structures into account, the nanoparticles observed were identified as $\mathrm{ZnO}$ nanoparticles. 


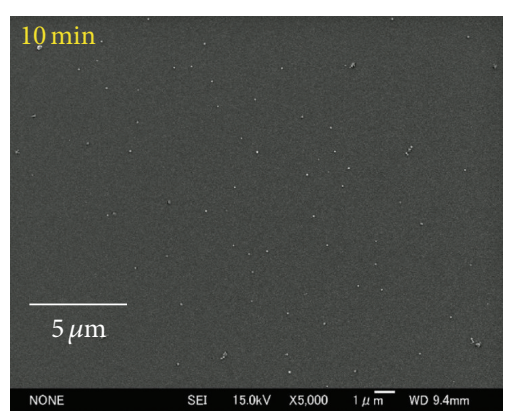

(a)

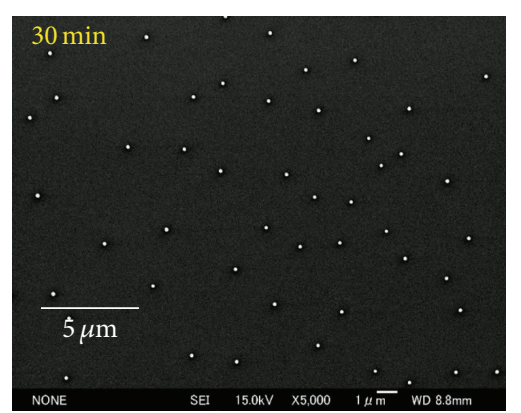

(b)

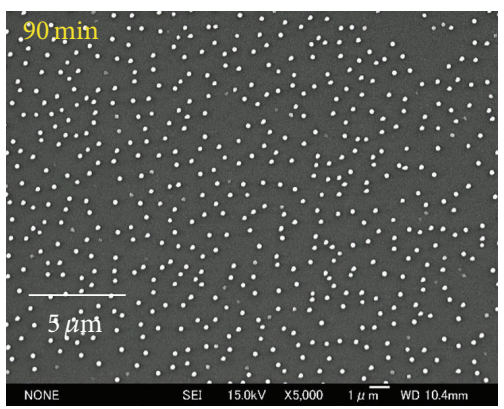

(c)

FIGURE 2: SEM images of particles deposited on Si substrate with deposition time as a parameter. Applied voltage $V_{p}$ is $-650 \mathrm{~V}$ and flow rate ratio of $\mathrm{Ar} / \mathrm{O}_{2}$ is $25 \mathrm{sccm} / 25 \mathrm{sccm}$.

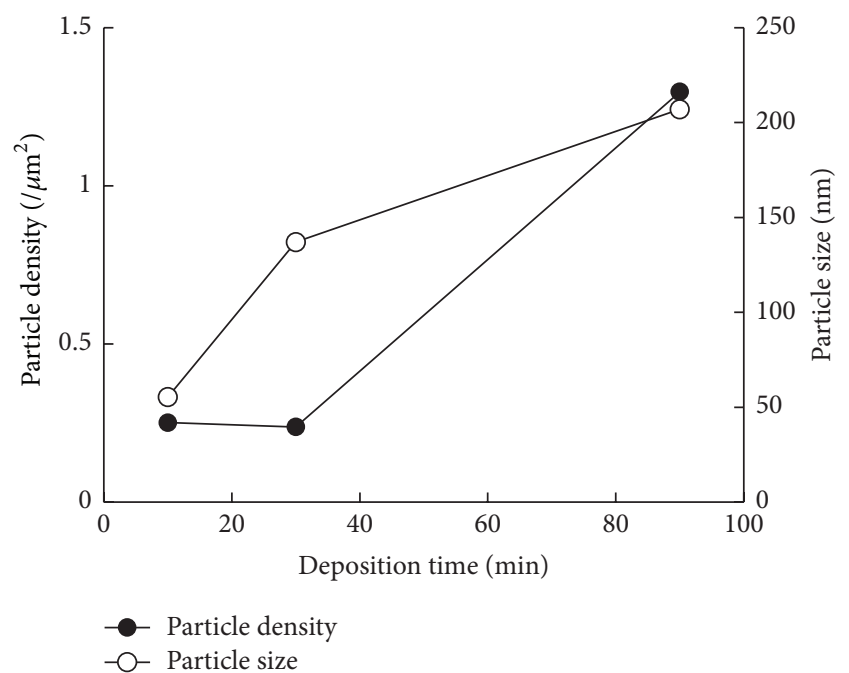

FIGURE 3: Variation of particle size and density as a function of the deposition time. Applied voltage $V_{p}$ is $-650 \mathrm{~V}$ and flow rate ratio of $\mathrm{Ar} / \mathrm{O}_{2}$ is $25 \mathrm{sccm} / 25 \mathrm{sccm}$.

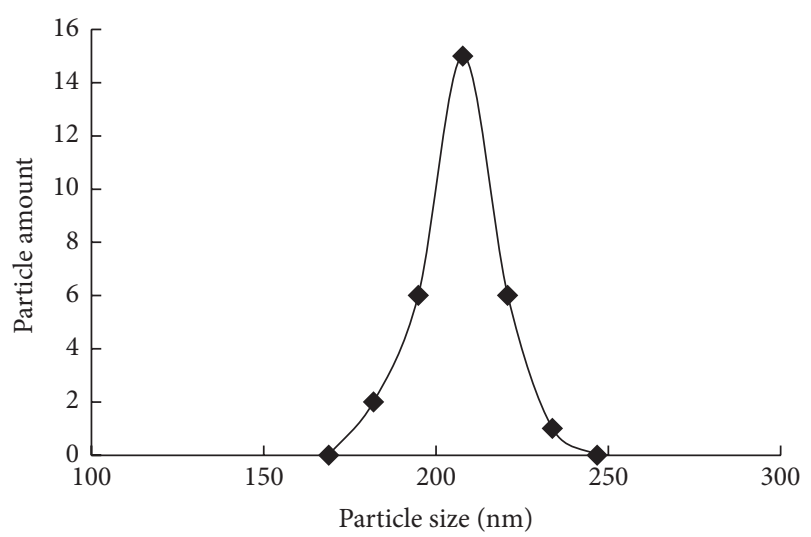

FIgUre 4: Particle size distribution function of the particles deposited on Si substrate after 90 minutes deposition.
3.3. Applied Voltage Dependence of Nanoparticle Deposition. Typical SEM images of the depositions on Si substrate were shown in Figure 7 with applied voltage $V_{p}$ as a parameter for 30-minute deposition. Very few particles were observed when $V_{p}=-500 \mathrm{~V}$. When applied voltage was below $-500 \mathrm{~V}$, almost no particle deposition was observed. However, with increasing the applied voltage, the number of particles was increased. When $V_{p}=-800 \mathrm{~V}$, we observed many particles deposited on Si substrate. The change of particle size and density was plotted in Figure 8 as a function of the applied voltage. When $V_{p}=-500 \mathrm{~V}$, the particle size was $140 \mathrm{~nm}$. The size was increased with $V_{p}$. It was remarkable that the particle deposition density was abruptly increased with $V_{p}$. When $V_{p}=-800 \mathrm{~V}$, the particle size was $190 \mathrm{~nm}$ and its density was 1.9 particles $/ \mu \mathrm{m}^{2}$. From this experiment, the applied voltage was very important for the production of $\mathrm{ZnO}$ nanoparticles. The uniformity of nanoparticle size was also preferable for a high voltage deposition.

3.4. Gas Flow Rate Dependence of Nanoparticle Deposition. Gas flow rate is also important factor for the particle deposition. Since in our case the oxidation of zinc took place on the surface of the zinc target, oxygen component ratio was important factor. Moreover, the oxidized zinc particles were sputtered by Ar ions. Therefore, the amount of Ar was also an important factor. We here fixed the gas flow rate ratio as $\mathrm{O}_{2}: \mathrm{Ar}=1: 1$. Only total flow rate of the mixed gas was changed when keeping the gas pressure constant by changing the pumping speed. Figure 9 shows SEM images for 3 different total flow rates, that is, $20 \mathrm{sccm}, 50 \mathrm{sccm}$, and $100 \mathrm{sccm}$. It became clear that the particle deposition was also depending on the gas flow rate. Very few particles were observed at $20 \mathrm{sccm}$. However, the number of particles was increased with the gas flow rate.

Figure 10 shows variation of particle size and density as a function of total gas flow rate. As shown in this figure, the particle density was saturated when the flow rate was $100 \mathrm{sccm}$; but the particle size was strongly dependent on the gas flow rate. The size was abruptly increased with 


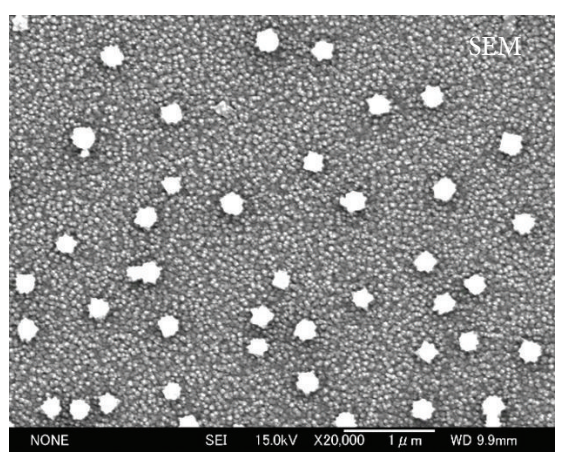

(a)

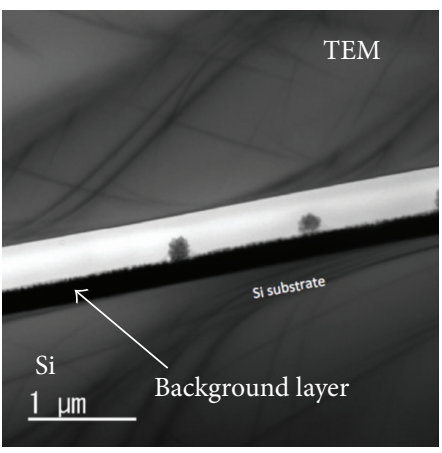

(b)

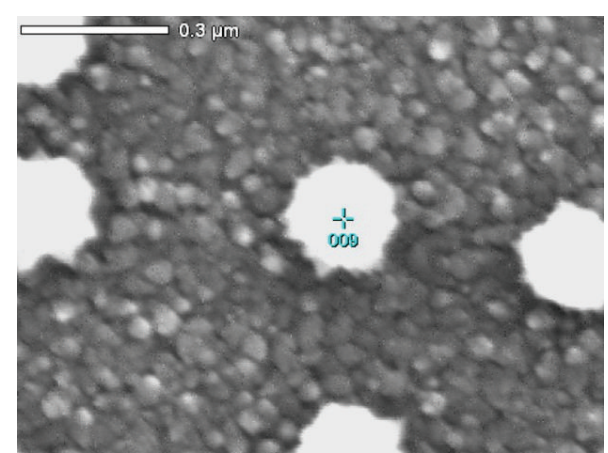

(c)

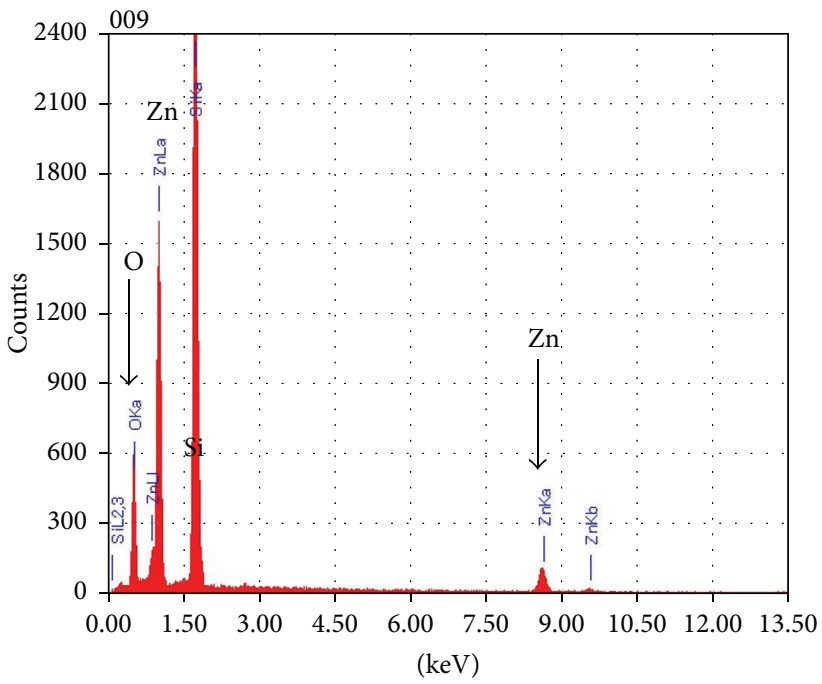

(d)

FIGURE 5: (a) SEM image of particles deposited on Si substrate. (b) TEM image of the cross section of (a). Nanoparticles on background surface layer deposited on Si substrate. (c) Magnified nanoparticles in (a). (d) EDX spectrum of nanoparticle marked by + on the particle in (c).

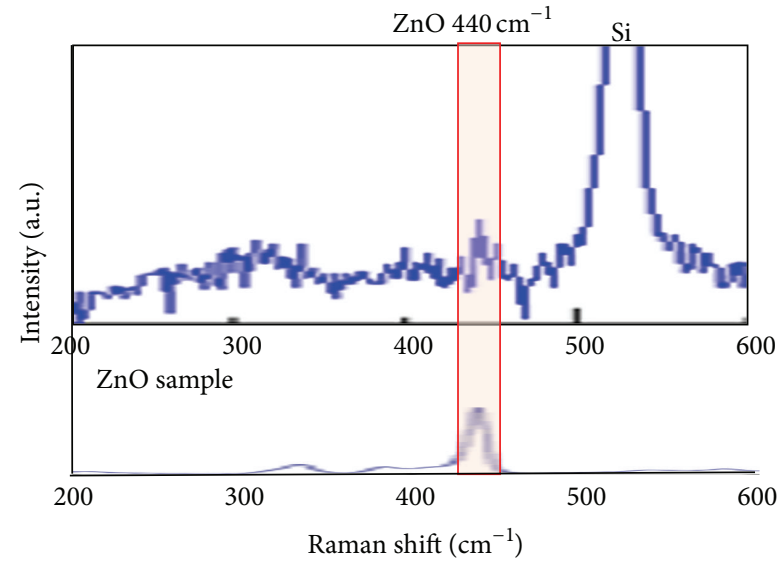

Figure 6: Raman spectra of the sample after 90 minutes deposition (upper trace) and $\mathrm{ZnO}$ standard sample (lower trace).

the flow rate. The particle density was 0.9 particles $/ \mu \mathrm{m}^{2}$ at total flow rate of $100 \mathrm{sccm}$. This dependency seemed to be closely related to a variation of plasma parameters such as electron density and electron temperature. We will discuss the mechanism in final section.

3.5. Plasma Parameter Measurement. The dependences of nanoparticle formation on the applied voltage and gas flow rate showed that the size and density of $\mathrm{ZnO}$ nanoparticles were able to be controlled by these experimental parameters. In particular, high voltage with a large amount of gas flow rate was a key parameter for getting a preferable nanoparticle yield. In order to understand particle size and density dependencies on the applied voltage and the gas flow rate, we carried out the plasma parameter measurement, that is, the electron density and electron temperature of the plasma produced.

Figure 11 shows the electron density and electron temperature as a function of the applied voltage. When the voltage was increased, the electron density increased in almost proportion to the applied voltage. Application of high voltage led to an increase of the electric field for the discharge, which resulted in a plasma density increase. On the other hand, the electron temperature was not much varied by the 


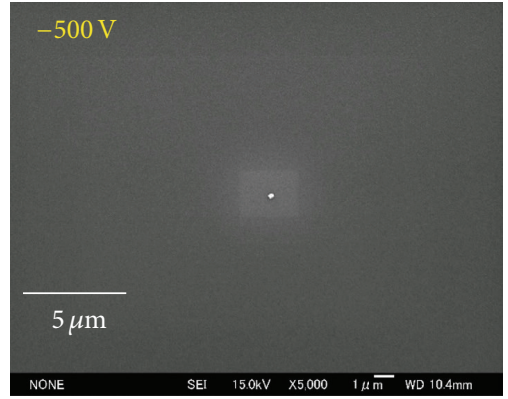

(a)

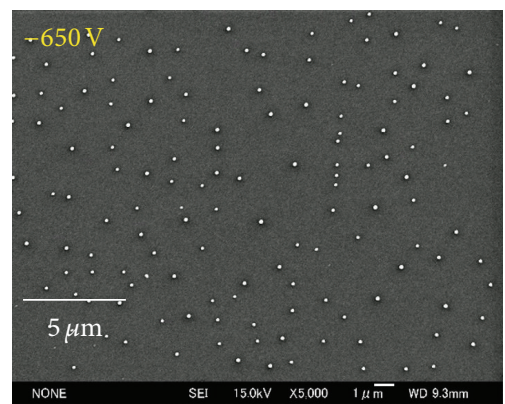

(b)

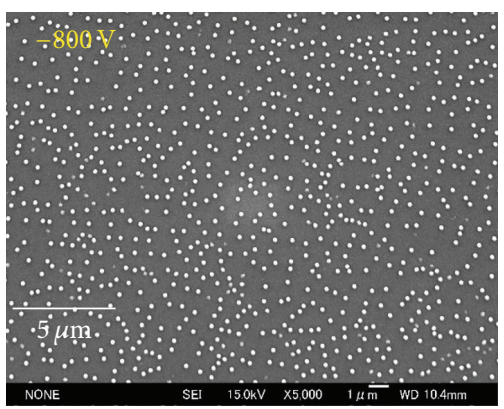

(c)

FIGURE 7: SEM images of particles deposited on Si substrate with applied voltage $V_{p}$ as a parameter. Flow rate ratio of $\mathrm{Ar} / \mathrm{O}_{2}$ is $25 \mathrm{sccm} / 25 \mathrm{sccm}$ for $30 \mathrm{~min}$ deposition.

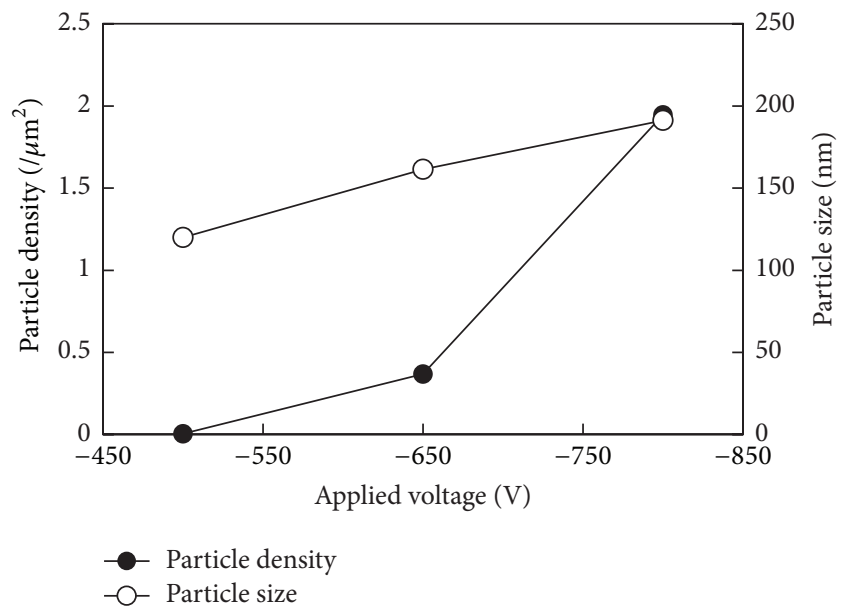

FIGURE 8: Variation of particle size and density as a function of applied voltage. Flow rate ratio of $\mathrm{Ar} / \mathrm{O}_{2}$ is $25 \mathrm{sccm} / 25 \mathrm{sccm}$ for 30 min deposition.

applied voltage. The energy absorbed by the electrons was mainly used for ionization and was not used for the increase of electron temperature.

The dependency of the plasma parameters on the total gas flow rate was shown in Figure 12. Although the electron temperature was almost constant, the electron density was increased with the gas flow rate, even when the total gas pressure was kept constant. The increase of the plasma density gave rise to an increase of the sputtering yield, which finally increased the number of nanoparticles. From these results, the plasma density was very important for the nanoparticle formation.

\section{Discussion}

As shown in Figure 5(b), $\mathrm{ZnO}$ nanoparticles were adhered to the surface of the background layer. Therefore, two mechanisms were considered. One was a mechanism for the formation of nanoparticles and the other was that for the formation of background surface films on Si substrate. Our results showed that nanoparticles and background thin layer were independently generated at the same time. The most important point was the fact that the nanoparticles were not buried in the background layer but were simply adhered to the top of the background layer.

This result showed that the nanoparticles were arrived at the substrate after the background layer formation. This meant that the nanoparticles were produced in a space of plasma and grew during their levitation in the discharge [1214]. It was well known that the nanoparticles were able to be negatively charged by the electrons and were levitating near the sheath edge in front of the wall. Owing to the gas flow, these levitating nanoparticles were carried toward the sheath edge in front of Si substrate and maintained for a long time by a force balance between the electrostatic force by the retarding electric field near the sheath edge and the neutral drag force by the gas flow toward the substrate. In this case, the gravity force might not be so effective, because the mass of nanoparticles was not so much heavy. On the other hand, the background layer was growing independently on the surface of Si substrate during the discharge.

We consider the following process. Since oxygen was fed in the gas phase with mixing ratio of $\mathrm{Ar} / \mathrm{O}_{2}=1 / 1$, zinc target surface was oxidized by $\mathrm{O}_{2}$ during the discharge. So, surface of $\mathrm{Zn}$ target would be covered by $\mathrm{ZnO}$ thin film. Therefore, an increase of the plasma density would cause an increase of the sputtering, by which $\mathrm{Zn}$ and $\mathrm{O}$ atoms were sputtered from the surface $\mathrm{ZnO}$ film into the gas phase. These atoms and $\mathrm{O}_{2}$ in the discharge would react to each other to produce $\mathrm{ZnO}$ molecules. Then, $\mathrm{ZnO}$ clusters were formed after molecular reaction. Since such atoms $(\mathrm{Zn}$ and $\mathrm{O})$, molecules $\left(\mathrm{O}_{2}\right.$ and $\mathrm{ZnO}$ ), and small size $\mathrm{ZnO}$ clusters were scarcely charged, they could arrive at Si substrate, which was known to be negatively biased during the discharge. Then, background surface $\mathrm{ZnO}$ layer was deposited as shown in Figure 5(b). On the other hand, since amount of charges by electron attachment increases with an increase in the particle size, $\mathrm{ZnO}$ clusters of larger size are charged negatively. So, they were electrostatically trapped in the sheath region in front of the negatively biased substrate. Finally, these charged $\mathrm{ZnO}$ clusters grew as $\mathrm{ZnO}$ nanoparticles by coagulation in the plasma space. Negatively charged particles were unable to attach to Si surface by a repulsive electric force. Therefore, 


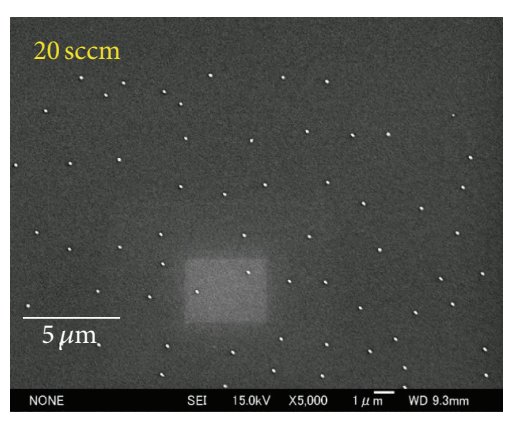

(a)

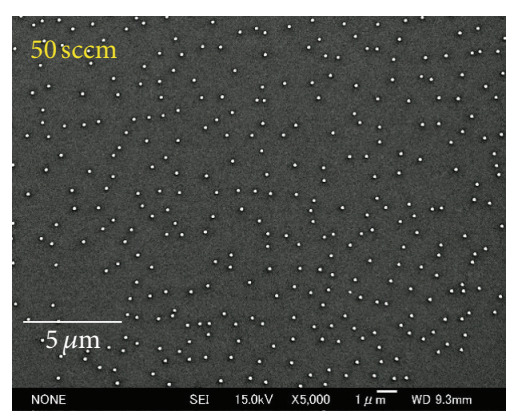

(b)

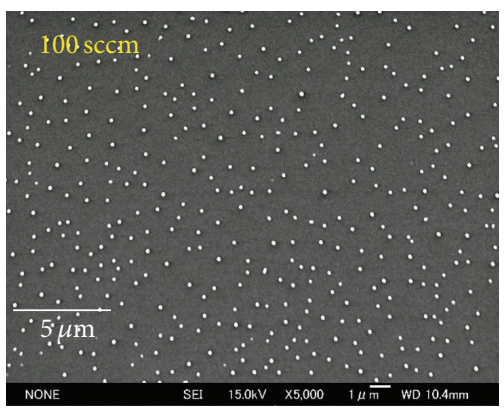

(c)

FIGURE 9: SEM images of particles deposited on Si substrate with total gas flow rate as a parameter. Applied voltage $V_{p}$ is $-650 \mathrm{~V}$ for 30 min deposition with flow rate ratio of $\mathrm{Ar} / \mathrm{O}_{2}$ being $1 / 1$.

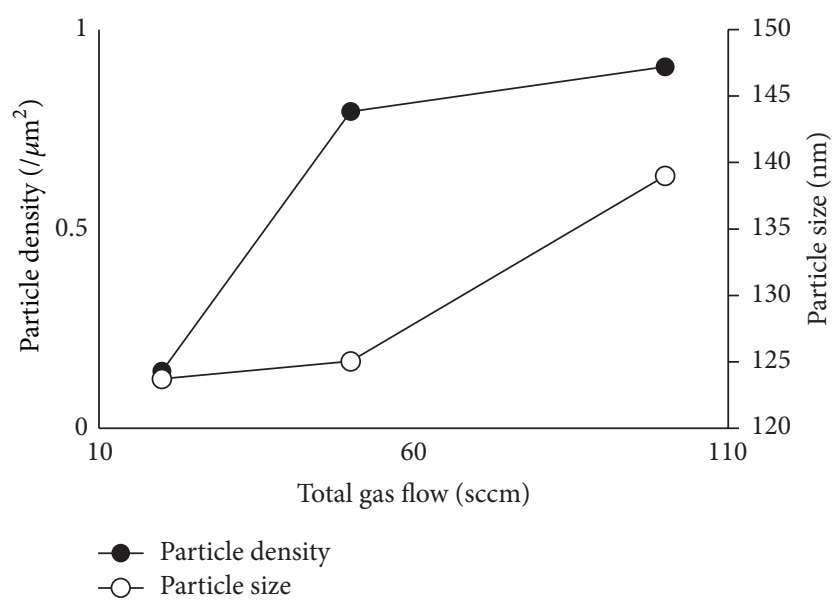

FIGURE 10: Variation of particle size and density as a function of total gas flow rate. Applied voltage $V_{p}$ is $-650 \mathrm{~V}$ for $30 \mathrm{~min}$ deposition with flow rate ratio of $\mathrm{Ar} / \mathrm{O}_{2}$ being $1 / 1$. Total pressure is fixed at $30 \mathrm{~Pa}$ by changing the pumping speed.

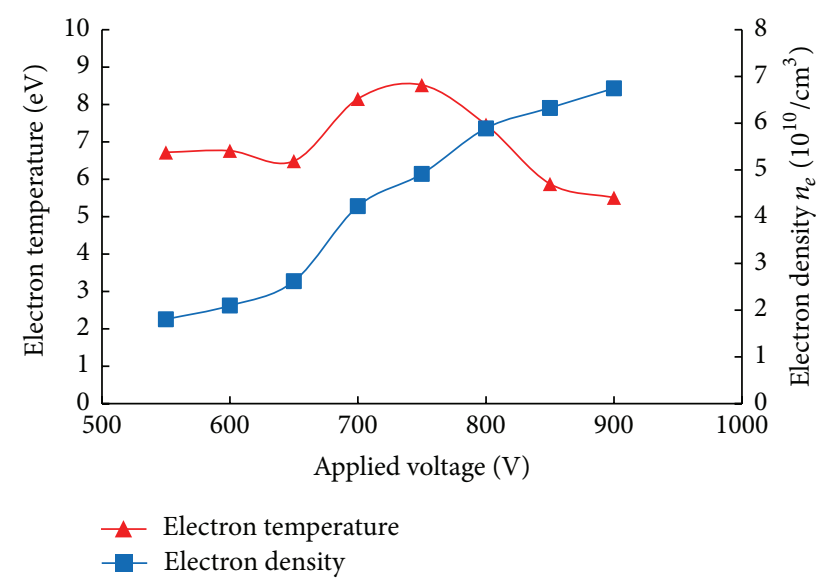

FIGURE 11: Variation of electron density and electron temperature of the plasma as a function of applied voltage.

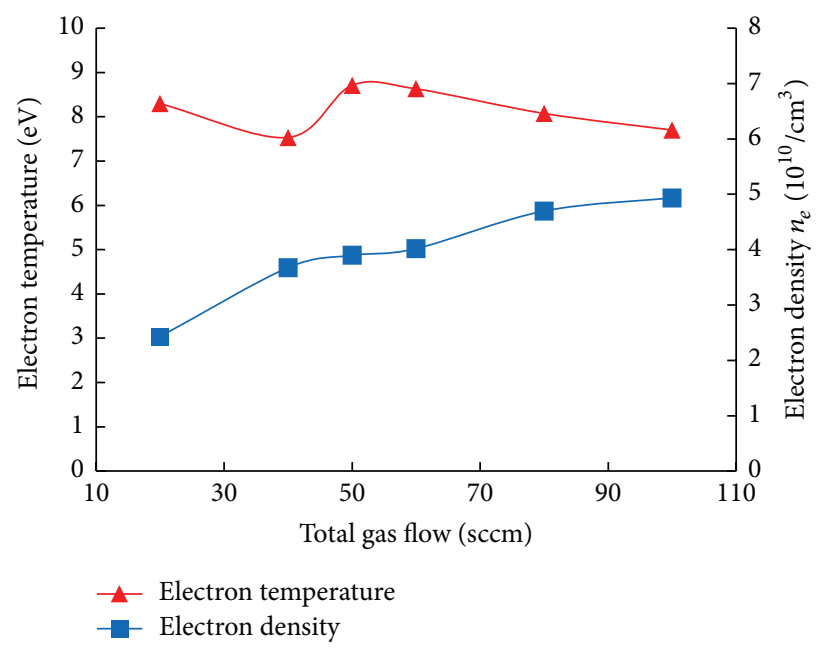

FIGURE 12: Variation of electron density and electron temperature of the plasma as a function of total gas flow rate.

nanoparticles were unable to be buried in the background layer during their growth during the discharge.

The above trapping and growth mechanism could also explain the reason why the particle size was so uniform as shown in Figure 4. It was known that mean value and standard deviation of the particle size were determined by successive generation of nucleation and growth depending on the plasma conditions. If the growth conditions are homogeneous in the plasma volume, the process of successive nucleation can be avoided and monosized particle distributions can be achieved, where very sharp particle size distribution could be obtained [15]. It was also shown that mean value of the particle diameter was varied by the deposition time and plasma conditions [15]. These results were well consistent with our results in Figures 2, 7, and 9.

When the plasma was turned off, electrons accumulated on Si substrate immediately leaked into the external circuit through semiconducting $\mathrm{ZnO}$ background layer. On the other hand, electrons on the negatively charged 
particles were slowly cancelled by positive ions flowing into the particles. In this way, after turning the discharge off, levitating nanoparticles with slowly decaying narrative charges were able to be transported and adhered to almost charge-free surface of the background layer on $\mathrm{Si}$ substrate.

It was also remarkable that the spacing of the particles, that is, particle-particle distance on Si substrate, was rather uniform as shown in Figures 2(c), 7(c), and 9(c). There was almost no place where the particles were so closely distributed and accumulated. Conversely, very vacant space where almost no particle existed was not observed. Mean distance among the particles on $\mathrm{Si}$ substrate was fairly uniform. The reason why they were so arranged with an almost equal particle distance was also related to their slowly decaying negative charges during the flight to the substrate. In the space of the plasma these charged particles were arranged with an almost equal distance during the levitation, forming a regular structure like a lattice in the solid state, by the Coulomb repulsive force. It was considered that these regular structures in the plasma space might be transferred and copied on the substrate surface when the plasma was turned off.

In application of this technique to quantum dot devices, for example, a small nanoparticle below a few $10 \mathrm{~nm}$ is required. In our experiment, nanoparticles of $55 \mathrm{~nm}$ were generated for $10 \mathrm{~min}$ deposition as shown in Figure 2. In order to generate small nanoparticles with size of $10 \mathrm{~nm}$, short deposition time with low gas flow rate will be effective in future. The importance of the deposition time on a formation of small nanoparticle was also pointed out in [15].

\section{Conclusion}

$\mathrm{ZnO}$ nanoparticles were generated under various conditions using a coaxial type electric discharge with $\mathrm{Ar} / \mathrm{O}_{2}$ mixed gas. The plasma parameters were measured and characteristic properties of the argon and oxygen plasma were clarified. By comparing with the deposition experiment, it was noted that high density plasma was important for the nanoparticle yield. The diameters of these nanoparticles could be varied in the range of $50-200 \mathrm{~nm}$ by controlling the applied voltage and the total gas flow rate.

It became clear that $\mathrm{ZnO}$ nanoparticles were created in the space of plasma and grew during their levitation under a force balance between the electrostatic force by the sheath edge electric field and the neutral drag force by the gas flow. When the discharge was turned off, these nanoparticles arrived at $\mathrm{Si}$ surface where $\mathrm{ZnO}$ background layer grew. This mechanism could also explain the size uniformity of the nanoparticles. The particle-particle spacing of these particles on $\mathrm{Si}$ substrate could be also explained by the particle charging model.

The coaxial electrode discharge system proposed here would be quite useful for growing $\mathrm{ZnO}$ nanostructures including nanoparticles.

\section{Conflict of Interests}

The authors declare that there is no conflict of interests regarding the publication of this paper.

\section{References}

[1] B. S. Li, Y. C. Liu, D. Z. Shen, J. Y. Zhang, Y. M. Lu, and X. W. Fan, "Effects of RF power on properties of $\mathrm{ZnO}$ thin films grown on $\mathrm{Si}\left(\begin{array}{lll}0 & 0 & 1\end{array}\right)$ substrate by plasma enhanced chemical vapor deposition," Journal of Crystal Growth, vol. 249, no. 1-2, pp. 179-185, 2003.

[2] F. K. Shan and Y. S. Yu, "Optical properties of pure and Al doped $\mathrm{ZnO}$ thin films fabricated with plasma produced by excimer laser," Thin Solid Films, vol. 435, no. 1-2, pp. 174-178, 2003.

[3] J.-H. Park, C.-B. Lee, I.-S. Kim, S.-J. Jang, and B.-T. Lee, “Effects of growth variables on the properties of single crystalline $\mathrm{ZnO}$ thin film grown by inductively coupled plasma metal organic chemical vapor deposition," Thin Solid Films, vol. 517, no. 15, pp. 4432-4435, 2009.

[4] H. Akazawa, "Highly conductive, undoped $\mathrm{ZnO}$ thin films deposited by electron-cyclotron-resonance plasma sputtering on silica glass substrate," Thin Solid Films, vol. 518, no. 1, pp. 2226, 2009.

[5] A. I. Ievtushenko, V. A. Karpyna, V. I. Lazorenko et al., "High quality $\mathrm{ZnO}$ films deposited by radio-frequency magnetron sputtering using layer by layer growth method," Thin Solid Films, vol. 518, no. 16, pp. 4529-4532, 2010.

[6] B. S. Li, Y. C. Liu, Z. Z. Zhi et al., "Effect of the growth temperature on $\mathrm{ZnO}$ thin films grown by plasma enhanced chemical vapor deposition," Thin Solid Films, vol. 414, no. 2, pp. 170-174, 2002.

[7] J. Tornow, K. Ellmer, J. Szarko, and K. Schwarzburg, "Voltage bias dependency of the space charge capacitance of wet chemically grown $\mathrm{ZnO}$ nanorods employed in a dye sensitized photovoltaic cell," Thin Solid Films, vol. 516, no. 20, pp. 71397143,2008

[8] A. J. Tzou, K. F. Chien, H. Y. Lai et al., "The study of selfassembled $\mathrm{ZnO}$ nanorods grown on $\mathrm{Si}(111)$ by plasma-assisted molecular beam epitaxy," Journal of Crystal Growth, vol. 378, pp. 466-469, 2013.

[9] H.-F. Lin, S.-C. Liao, and C.-T. Hu, "A new approach to synthesize $\mathrm{ZnO}$ tetrapod-like nanoparticles with DC thermal plasma technique," Journal of Crystal Growth, vol. 311, no. 5, pp. 1378-1384, 2009.

[10] K. Kumeta, H. Ono, and S. Iizuka, "Formation of $\mathrm{ZnO}$ nanostructures in energy-controlled hollow-type magnetron RF plasma," Thin Solid Films, vol. 518, no. 13, pp. 3522-3525, 2010.

[11] T. Muraoka, T. Kashimura, and S. Iizuka, "Spherical MgO microparticle deposition by RF impulse discharge with small coaxial electrodes," Thin Solid Films, vol. 518, no. 3, pp. 10121015, 2009.

[12] G. Nishimura, S. Iizuka, T. Shimizu, and N. Sato, "Diamondparticles levitated in a reactive plasma," Diamond and Related Materials, vol. 12, no. 3-7, pp. 374-377, 2003.

[13] S. Iizuka and T. Muraoka, "Single-crystal MgO hollow nanospheres formed in RF impulse discharge plasmas," Journal of Nanomaterials, vol. 2012, Article ID 691874, 6 pages, 2012.

[14] Y. Yamazaki and S. Iizuka, "Formation of nanospheres and nanorods of titanium dioxide in a low-pressure $\mathrm{Ar} / \mathrm{O}_{2}$ plasma 
controlled by a sputtering method," International Journal of Material Science, vol. 3, no. 4, pp. 163-169, 2013.

[15] L. Boufendi, A. Plain, J. P. Blondeau, A. Bouchoule, C. Laure, and M. Toogood, "Measurements of particle size kinetics from nanometer to micrometer scale in a low-pressure argon-silane radio-frequency discharge," Applied Physics Letters, vol. 60, no. 2, pp. 169-171, 1992. 

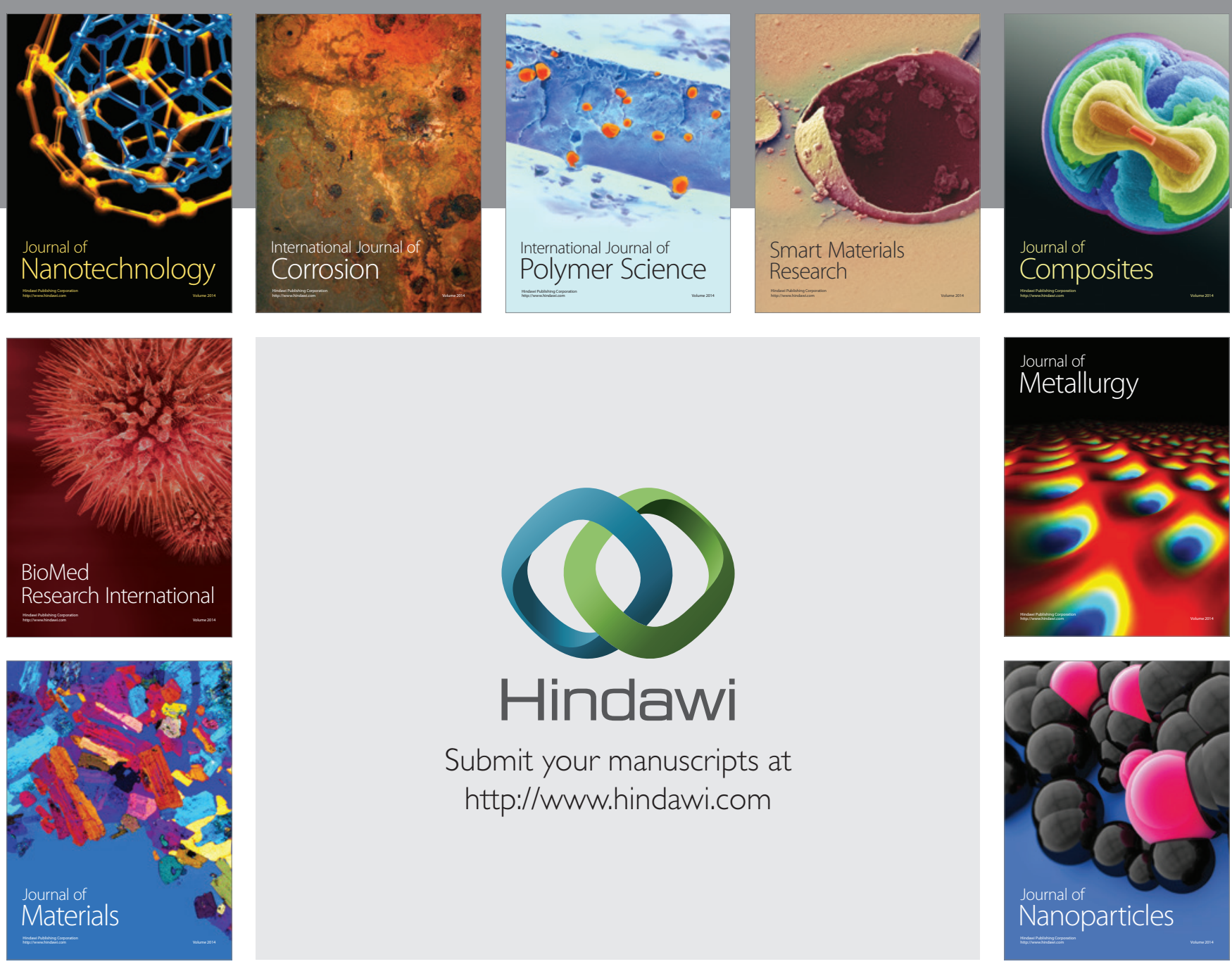

Submit your manuscripts at http://www.hindawi.com
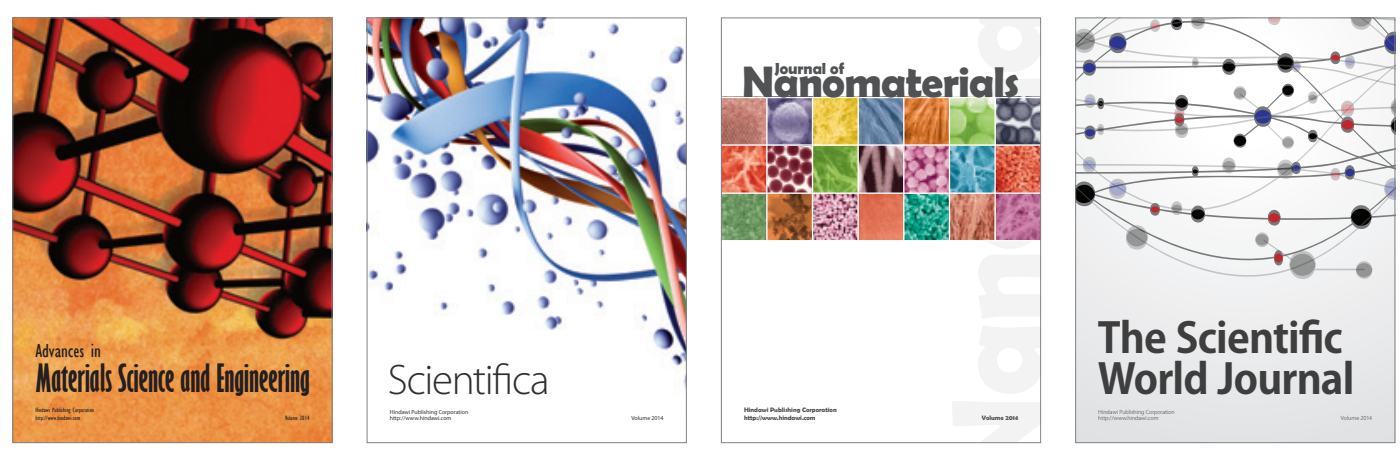

\section{The Scientific World Journal}
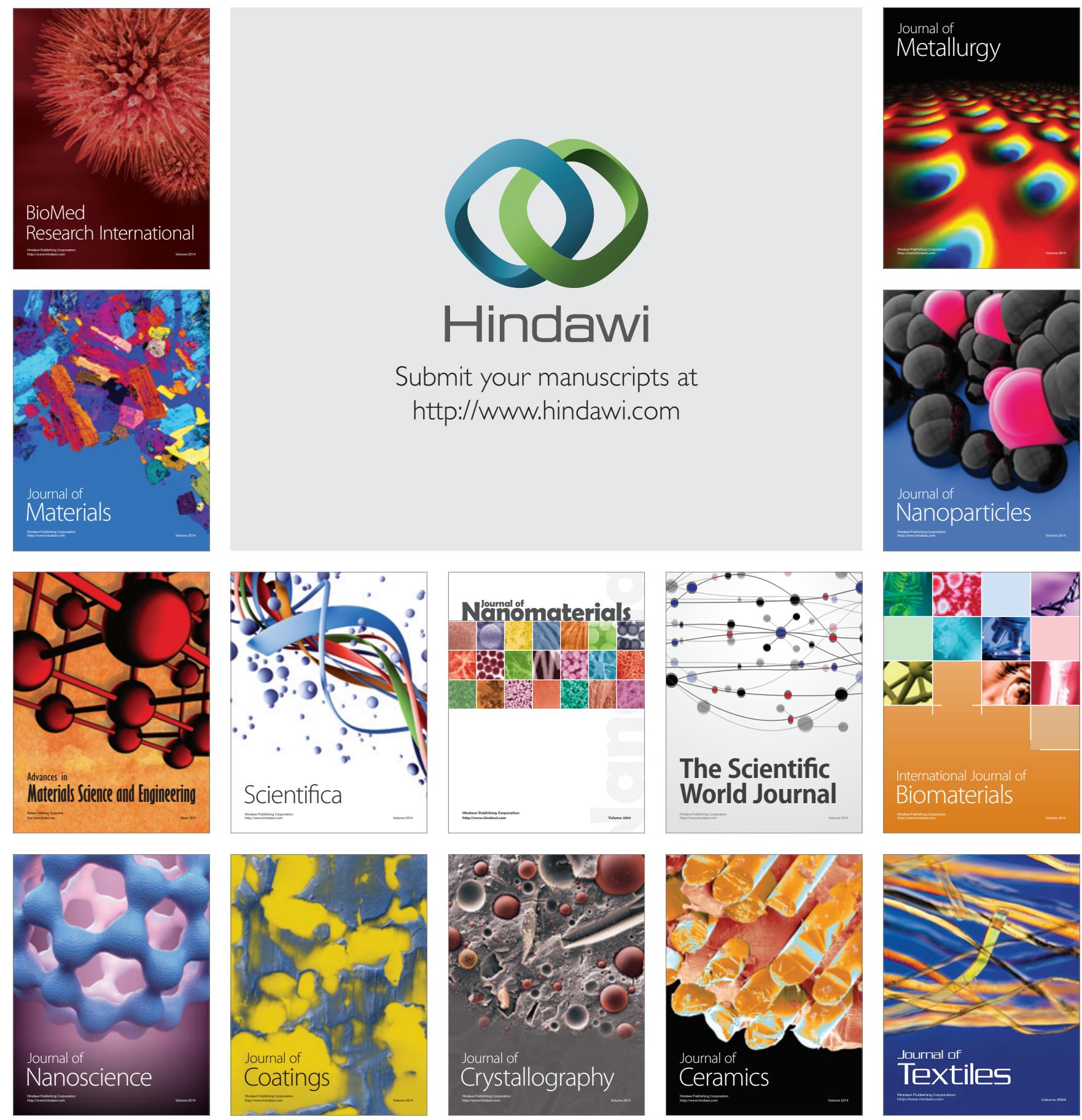